\title{
Selection of Ecologically Efficient and Energetically Economic Engineering-Ecological System for Municipal Solid Wastes Transportation
}

\author{
Vadim Bespalov ${ }^{1}$, Oksana Paramonova $^{1}$, Oksana Gurova $^{1}$, and Natalia Samarskaya ${ }^{1}$ \\ ${ }^{1}$ Architectural and Construction Academy Don State Technical University, 344022, \\ Sotsialisticheskaya str. 162, Rostov-on-Don, Russia
}

\begin{abstract}
Sanitary city cleaning is one of the most important sanitary and hygiene events, promoting protection of human health and environment. Sanitary cleaning includes a complex of works on solid municipal wastes (SMW) collection, transportation, deactivation, processing and burial and urban territory cleaning. In order to improve the works on SMW handling and the ecological state of urban territories, enterprises of public and utility sphere operate, organizing all types of works listed above. However, processes of waste creation and accumulation are dynamic in their essence. Process of waste transportation depends on various factors. Management of this process often demands urgent correcting of earlier taken decisions or even cancellation of those decisions. Reasons of such changes could be of the most unpredictable nature, for example, traffic jams on motorways, vehicles breakage, repair works on the roads, etc. Thus, the enterprise (or, more precisely, the facilities serviced by it, the transport) acting with the purpose of providing ecological safety to urban territories, is the source of E pollution by itself. One of the main stages of SMW handling is waste transportation, where sources of E pollution with wastes (accumulation points) and enterprises on handling SMW are involved. That is why the solution of the pressing issue of increasing ecological safety of urban territories on the basis of ecologically efficient and energetically economic selection of engineering-ecological system of SMW transportation is represented in the article.
\end{abstract}

\section{Introduction}

Vigorous rates of development of urban territories are accompanied with increase of load on E, including the growth of the number of created SMW. Substantial changes have happened lately in the structure and characteristics of SMW, which demands, in its turn, more advanced approach in implementation of efficient systems of their handling. Realization of such systems should be implemented in the direction of provision of growing demands to adherence to E quality and sanitary well-being of the population.

Results of research dedicated to changes of SMW characteristics, system of wastes handling in the territories of populated areas in general and its certain elements, in 
particular, are represented in works of such Russian and foreign authors, as V.M. Garin, A.N. Mirniy, V.I. Smetanin, L.Ya Shubov, R. Murray, R. Bendere, F. R. McDougall, P. R. White, N. G. Turan and others [1-24].

Existing situation in the sphere of SMW handling demands making immediate decisions in the part of creation of modern ecologically efficient and energetically economic engineering-ecological systems of SMW handling, providing for implementation of modern wastes collection, transportation, processing and burial technologies. Such technologies could be realized with the help of different methods, ways and technical means [7, 11, 2527], the choice of which is made, as a rule, on basis of economic comparison of several variants and simplicity of technical realization. At that only indicated economic expenses on their realization are used as criteria for selection of such technologies.

Improvement of the system of SMW handling, based on minimization of wastes creation and absolute processing of the majority of their fractions with maximum use of material and energy potential will allow to ecologically efficiently and energetically economically manage the movement of wastes flows, going the way of transition from traditional SMW handling to their resource use by application of engineering-ecological means, providing for implementation of wastes transportation, as one of the major stages of SMW handling, which, in the end, determines the actuality of the research topic.

\section{Theory or experimental methods}

SMW are the sources of secondary material and energetic resources, use of which allows to reduce the load on $\mathrm{E}$ and decrease the consumption of natural resources [1-3, 28-31], which is one of the main tasks to implement the system of SMW handling in the urban territories.

SMW negatively affects the E on each stage of their "life cycle" [33-39], that is why means to reduce this impact $[40,41]$ shall be provided for each stage in the system of their handling. Thus, for the stage of SMW creation in the process of their "life cycle" in the system of wastes handling their collection is provided for, for the stage of accumulation transportation; for SMW distribution in E - disposal.

Main stages of the process of E pollution [42], thus, are laid as basis for development of special engineering-ecological events $[40,41]$, the essence of which is in minimization of creation, accumulation and distribution of SMW. The earlier in the pollution process special engineering-protective events are realized, the less expenses are necessary for their organization.

To prevent distribution of SMW in E, which have been collected and directed for implementation of the next stage, systems of transportation and handling (burial) are technologically provided for.

Main condition for the solution of the task for provision of ecological safety of urban territories is highly efficient and energetically economic realization of SMW transportation, the essence of which, in our opinion, is in localization (prevention of distribution) of SMW in the limited zone, provided for beforehand (places of accumulation). SMW transportation could be implemented as:

- removal inside premises with the help of garbage disposals;

- removal from the limited zone (in the places of accumulation on the urban territory) into the sorting stations (if necessary) and processing;

- further transportation into the places of disposal (burial) [25, 43, 44].

As the practice of use of garbage disposals systems in residential multi-storied buildings evidences, their only advantage is convenience for the residents when there is no necessity to carry garbage to the wastes container located outside the building. The disadvantages are as follows: impossibility to organize separated collection; distribution of foul smells, insects, rats in case of mistakes in exploitation, antisanitary state of reception devices; 
inconvenience of maintenance. Pneumatic transport could also be used for transportation of wastes inside the premises (due to difference of pressures created by vacuum or feed pump) and hydrotransport.

As the analysis of world experience evidence, all the variety of used systems of SMW transportation from the collection points to the places of their utilization could be limited by two main ones - direct (one-stage) and double-stage with various modifications.

More often four main types of SMW transportation are used:

- direct transportation by collecting dump trucks (for collection of SMW nonchangeable containers are used);

- direct transportation using dump trucks with changeable containers;

- double-stage transportation with intermediary transshipment at the dump transshipment stations (DTS);

- mixed transportation, when part of SMW is transported via DTS, and part - directly $[25,43,44]$.

Single stage transportation of SMW is used in direct transportation from the places of the creation (collection) and accumulation (container grounds, etc.) to the facilities of infrastructure on their further disposal using special or equipped transportation vehicles dump trucks of various types and modifications, cargo vehicles, etc. Traditionally single stage disposal of SMW is carried out using collecting dump trucks of minor and middlescale capacity which transport the wastes directly to the places of their handling (sorting, utilization, burial).

Double stage transportation with intermediary transshipment at DTS is usually used in major and middle-size cities when processing facilities are rather distant (more than 17-25 $\mathrm{km}$ ) for utilization (burial) of SMW from the places of their creation and includes use of DTS on the ways of removal of SMW from the places of their creation (collection) and accumulation to the facilities of infrastructure for further handling using different dump trucks.

Transportation of SMW from the source of their creation is carried out by minor and middle-size collecting dump trucks. Transportation from DTS is usually carried out by major vehicles of various modifications: with removable containers, compacted; with compaction of SMW directly in the transportation dump truck; with press containers; packed into bags after compaction at DTS, etc. In double stage transportation using DTS expenses for transportation of SMW from the places of their creation and collection to places of their further handling are reduced. At that the number of dump trucks reduces, general emissions into the atmosphere from dump trucks is decreased, intensity of vehicles movement on the motor roads is reduced, SMW burial technology is made easier [25, 43, 44].

Mixed transportation is used in cases when part of the flow of transported SMW is directed to DTS, which are located where it is necessary due to economic criteria, and other wastes are transported directly, without DTS [25, 43, 44].

Depending on the accepted type of transportation of SMW, amount of created SMW, used type of collection (mixed, separate, incomplete separate), distance between the infrastructure facilities on SMW handling and places of SMW creation, population density, planning of an inhabited area, climatic and geographic peculiarities, economic possibilities, etc selection and calculation of the necessary amount and types of transport for SMW transportation is carried out [25, 43, 44].

For transportation of SMW presently different dump trucks are used, manufactured both locally and of foreign manufacturers with different purpose of use, capacity, loading and unloading mechanism, special equipment for compaction of SMW and nature of the compaction process. 
Abundance of technical means with different characteristics explains the relevance of the problem of selection of events on E protection from SMW. In this case different criteria should be taken into consideration, taking into account economic, social, ecological and other aspects of this problem [11, 12, 25, 46-48].

In our opinion, for provision of ecological safety of urban territories during transportation of SMW it is viable to use as resulting criteria for selection ecological efficiency and energetic economy [40, 41, 49].

Thus, the choice of optimal engineering-economic system for transportation of wastes for the set conditions of urban territory during SMW handling shall help the evaluation of expedience of use of the chosen technology.

\section{Experimental section}

Methods of examination are based on the main statements of the theory of dispersion systems, system analysis, analytical generalization of the known scientific and practical results.

\section{Results and Discussion section}

To determine parameters of transportation and its constructive design knowledge of main physical and mechanical, physical and chemical and energetic characteristics of wastes and laws of their changes under the influence of various factors is necessary.

In accordance with $[25,40,41]$ SMW transportation is characterized by ecological efficiency which determines the degree of reduction of amount of SMW $\left(\mathrm{M}_{1}-\mathrm{M}_{2}\right)$ related to initial amount of created wastes $\left(\mathrm{M}_{1}\right)$ due to use of technical means for collection and is described in general with the following dependence:

$$
E_{e f(\text { trans })}=\frac{M_{1(\text { transpor })}-M_{2(\text { transpor })}}{M_{1(\text { transpor })}} \cdot 100, \%
$$

where $E_{\text {ef (transport) }}$ is design efficiency of implementation of SMW transportation, \%; $M_{l_{\text {(transport) }} \text { is }}$ actual initial specific quantity of SMW, collected and accepted into the transportation vehicle for transportation of SMW to the places of further handling, $\mathrm{kg} / \mathrm{t}$ (t/year); $M_{2 \text { (transport) }}$ - actual final specific quantity of SMW transported for realization of the further stage of handling taking into consideration irrecoverable losses, $\mathrm{kg} / \mathrm{t}(\mathrm{t} / \mathrm{year})$.

However formula (1) could be used only in cases when there is a possibility of measuring corresponding values of masses of SMW components, which under the conditions of actual populated area is rather difficult. In this case it is necessary to use parametric dependence of ecological efficiency for SMW transportation [25].

Research of physical essence of the process of SMW transportation allowed to botain parametric dependence of ecological efficiency of SMW transportation for the conditions of an urban territory $[1,25,28,31,32]$

$$
E_{\text {ef (tranport) }}=\sum_{j=1}^{n}\left[\left(1-\left(1-2,4 \cdot\left(\frac{B \cdot V_{S M W}}{\mu_{v} \cdot V_{\text {cap. }} \cdot D_{\text {eqd }}^{2}}\right)^{1,5} \cdot\left(1-0,055 \pi \cdot \mu_{v} \cdot D_{\text {eqd }}{ }^{2}\right)\right) \cdot\left(K_{\text {com }} \cdot K_{\text {exp }}\right)\right]\right. \text {, }
$$


where $B \approx 10^{-26}$ - is the permanent of intermolecular interaction, $\mathrm{J} \cdot \mathrm{m}^{2} ; V_{S M W}-$ is the specific volume of created SMW, $\mathrm{m}^{3} /$ year;

$\mu_{v}$ - is the dynamic air viscosity, Pa.s; $V_{c a p}-$ is the vehicle capacity, $\mathrm{m}^{3} ; D_{e q d}-$ is the equivalent diameter of SMW particles, m; $K_{c o m}-$ is the compaction coefficient; $K_{\text {exp }}-$ is the expansion coefficient.

Taking into account that energetic economy (energy intensity index) is considered also a rather important resulting parameter, which characterizes the share of energy spent on achievement of the purpose of the process of decrease of pollution (useful energy) $\left(\Sigma \mathrm{W}_{\mathrm{i}}\right)$, related to the energy spent on realization of the process in general $\left(\Sigma \mathrm{N}_{\mathrm{i}}\right)$, for the conditions of certain urban territory or its part, we have obtained its parametric dependence, as well [1, $25,28,31,32]$ :

$$
E=\frac{0,033 \cdot 10^{-25} \cdot \sum_{j=1}^{n} m_{v . s .} \cdot V_{c a p} \cdot n \cdot S+\sum_{j=1}^{n} \frac{F_{a d h} \cdot S}{\pi \cdot \tau_{a d h}}+\frac{M_{S M W}}{\rho_{\text {in }}^{S M W}} \cdot \int_{v i n}^{v f i n} \sigma(\rho) \partial^{\prime} v}{\sum_{j=1}^{n} N_{1}+N_{2}+\ldots+N_{n}}
$$

where $m_{\text {v.s. }}-$ is the vehicle size, $\mathrm{m} ; V_{\text {cap }}-$ is the vehicle capacity, $\mathrm{m}^{3} ; n$ - number of collected into $1 \mathrm{~m}^{3}$ of tank of SMW per unit of time, $1 /\left(\mathrm{m}^{3} \cdot \mathrm{s}\right) ; S-$ is the area of the surface of cleaning territory, $\mathrm{m}^{2} ; \mathrm{F}_{a d h}$ - is the area of adhesion interaction of particles directed into the unit of volume $\left(\mathrm{m}^{3}\right)$ for collection, $\mathrm{m}^{2} / \mathrm{m}^{3} ; \tau{ }_{\text {adh }}-$ is the time of adhesion interaction, $\mathrm{c}$; $\rho_{\text {in }}{ }^{S M W}$ - is the initial density of SMW, $\mathrm{kg} / \mathrm{m}^{3} ; V_{\text {in }}, V_{\text {fin }}$ - are the integration limits equaling the SMW volume on the initial and final moments of compaction, $\mathrm{m}^{3} ; \sigma(\rho)-$ is the symbol of interconnection of stresses and density of SMW; $\Sigma \mathrm{N}_{\mathrm{i}}$ - is the energy spent on realization of the process in general.

Improvement of the system of SMW handling should be based on the analysis of parametric dependencies of resulting transportation parameters - ecological efficiency and energy intensity index, allowing to manage this process.

As the variables one should choose those functionally independent parameters the changes of which leads to simultaneous increase of values of both efficiency and energy economy (energy intensity index).

Thus, as the result of the research held we have achieved the possibility of provision of ecological safety on certain parts of urban territories at the account of prevention of SMW losses by increasing efficiency and economy of transportation, and also improvement of technical means for their realization.

\section{Conclusion}

The obtained parametric dependencies of ecological efficiency and energy intensive index of the implementation of the process of SMW transportation most fully reflect the peculiarities of SMW interaction with certain functional elements of the system of decrease of negative impact of SMW on E and could be used as optimization criteria for forecast and evaluation of the degree of ecological safety and energetic economy of different variants of such systems.

The abovementioned criteria of selection of ecologically efficient and energetically economic engineering-ecological system for SMW transportation allows also to simulate the result of implementation of this process taking into account adherence to sanitaryhygiene and ecological norms. 


\section{References}

1. V.V. Zhurkovich, A.I. Potapov, Municipal waste (2001)

2. A.N. Mirniy, Communal ecology: Encyclopedic Handbook (2007)

3. A.S. Grinin, V.N. Novikov, Industrial and domestic waste: storage, disposal, recycling (2002)

4. L.Y. Shubov, A.K. Golubin, V.V. Devyatkin, Concept of solid waste management (2000)

5. E.E. Borovsky, Industrial and domestic waste: environmental problems (2007)

6. V.M. Garin, N.A. Klenow, A.G. Tail, technology and utilization of waste (2005)

7. V.A. Grachev, A.T. Nikitin, S.A. Fomin, Handling the production and consumption of ecological safety system wastes (2008)

8. V.I. Smetanin, Environmental protection from waste production and consumption (2003)

9. I. Babanin, Recycle Revolution. How to solve the waste problem at minimal cost (2008)

10. L.N. Beldeeva, S. Lazutkina, L.F. Komarova, Environmentally sound management of waste (2006)

11. A.G. Vetoshkin, Protection of the lithosphere of waste (2005)

12. B.B. Bobovich, Processes and recycling machines (2013)

13. I.M. Sharohovskaya, Waste recycling, 1 (13), 54-61 (2008)

14. V.M. Shmandy, Management of technogenic safety urbosistemy at Obration stage and waste into the environment, 2, 152 (2001)

15. N. G. Turan et al., Waste Management, 29, 465-469 (2009)

16. R. Murray, Target - Zero Waste (2004)

17. Ruta Bendere, Waste management (2003)

18. Forbes R. McDougall, Peter R. White, Marina Franke, Peter Hindle, Integrated Solid Waste Management: A Life Cycle Inventory, (2008)

19. J. H. Tanskanen, Resources, conservation and recycling, 30, 2, 111-133 (2000)

20. M Sharholy et al., Waste management, 27, 4, 490-496 (2007)

21. K. N.Kumar, S.Goel, Resources, Conservation and Recycling, 53, 3, 166-174 (2009)

22. C. Visvanathan, J. Trankler, Workshop on Sustainable Landfill Management, 3-5 (2003)

23. K.Ravindra, K.Kaur, S.Mor, Journal of Cleaner production, 89, 251-256 (2015)

24. M. A. Abas, S. T. Wee, Municipal solid waste management in Malaysia: An insight towards sustainability, (2014)

25. Ya. Weisman, V.N. Korotaev, N.N. Slyusarev, Waste Management. Collection, transport, compaction, sorting municipal solid waste (2012)

26. L.Y. Shubov, M.E. Stavrovsky, A.V. Olejnik, Technology of municipal solid waste (2013)

27. V.I. Bespalov, O.N. Paramonova, Collection of Scientific Papers SWorld. Scientific research and its practical application. Current status and development trends 2012, 3(9), 89 (2012) 
28. URL: http://portaleco.ru/ekologija-goroda/sostav-svojstva-i-obem-tverdyhbytovyh-othodov.html

29. URL: http://naukovedenie.ru/PDF/33trgsu513.pdf

30. URL: http://www.webcitation.org/6DpWIgJOW

31. URL: http://ivdon.ru/magazine/archive/n3y2013/1933

32. O.N. Paramonova, E.P. Lysova, Problems of reclamation of waste household, industrial and agricultural production: Materials of IV International scientific ecological conference, 2, (2015)

33. O.N. Paramonova, Environmental Economics and Conservation, 58-61 (2013)

34. R.G. Adamyan, Building-shaping the built environment, 262-265 (2013)

35. V.V. Privalenko, I.N. Kuznetsov S.G. Demchenko, Ecological and geochemical monitoring of landfills SMW of Rostov-on-Don (2009)

36. D.Özeler, Ü.Yetiş, G. N. Demirer, Environment International, 32, 3 405-411 (2006)

37. A. S. E. Yay, Journal of Cleaner Production, 94, 284-293 (2015)

38. M. A. Rajaeifar et al. , Renewable and Sustainable Energy Reviews, 51, 886-898 (2015)

39. E.A. Ivantsova, Messenger Volgograd State University, Episode 3: The Economy. Ecology, 2 (35) (2016)

40. V.I. Bespalov, O.N. Paramonova, Modern scientific achievements in 2013, 92-96 (2013)

41. V.I. Bespalov, O.N. Paramonova, Modern Problems and solutions in science, transport, manufacturing and education in 2012, 76-80 (2012)

42. URL: http://ivdon.ru/magazine/archive/n4p1y2012/11

43. S.Das, B. K. Bhattacharyya, Waste Management, 43, 9-18 (2015)

44. G. K. Singh, K.Gupta, S. Chaudhary, International Journal of Environmental Science and Development, 5, 4, 347 (2014)

45. A..M. Gonopolsky, A. A. Timofeeva, Ecology, 3, 36-41 (2016)

46. V.I. Bespalov, O.N. Paramonova, Geology problems, planetary, geo-ecology and rational wildlife, 265-267 (2011)

47. V.I. Bespalov, O.N. Paramonova, Ecology and Life, 22-25 (2011)

48. O.N. Paramonova, Recent scientific questions: Reality and Perspectives, 6, 112114 (2012)

49. Z. Yang, X. Zhou, L. Xu, Journal of Cleaner Production, 104, 242-249 (2015) 